\title{
Silicon isotopes in SNC meteorites : a record of accretion or differentiation of Mars?
}

\author{
DELPHINE LOSNO ${ }^{1}$, CAROLINE FITOUSSI ${ }^{2}$ AND \\ BERNARD BOURDON ${ }^{2}$
}

${ }^{1}$ LGLTPE-Laboratoire de Géologie de Lyon

${ }^{2}$ Laboratoire de Géologie de Lyon Terre Planètes Environnement

Presenting Author: delphine.losno@ens-lyon.fr

The bulk chemical composition of terrestrial planets such as Mars is still uncertain, even for major elements such as iron, magnesium and silicon. The analysis of the stable isotopic composition of these elements may help understand the processes that have built terrestrial planets and ultimately constrain their bulk composition. As other terrestrial planets, Mars exhibits a depletion in volatile elements and is enriched in refractory lithophile elements. The processes that have led to these characteristics are poorly constrained: they may stem from the building blocks or from processes taking place during accretion such as impacts, magma ocean or core formation.

In this study, we have analyzed twelve martian meteorites for their $\mathrm{Si}$ isotopes, as previous studies have shown a dispersion in $\mathrm{Si}$ isotopes with no systematic variations $[1,2,3]$. Our goal was to examine whether the $\mathrm{Si}$ isotopes in martian meteorites recorded an event of volatile loss as has been observed with $\mathrm{Mg}$ and possibly Si isotopes in the Earth. Our results show a range in $\mathrm{Si}$ isotopes suggesting that post-accretion processes must have affected the $\mathrm{Si}$ isotope signature.

[1] Armytage et al. (2011), Geochim Cosmochim Acta, 75, 3662-3676 [2] Zambardi et al. (2013) Geochim Cosmochim Acta, 121, 67-83 [3] Pringle et al. (2013), PNAS, 48, 17029-17032. 